\title{
Does T3 Subdivision Correlate with Nodal or Distant Metastasis in Colorectal Cancer?
}

\author{
Hong Yeol Yoo, Rumi Shin, Heon-Kyun Ha, Heung-Kwon Oh, Seung-Yong Jeong, Kyu Joo Park, \\ Gyeong Hoon Kang ${ }^{1}$, Woo Ho Kim ${ }^{1}$ Jae-Gahb Park \\ Departments of Surgery and ${ }^{1}$ Pathology, Seoul National University College of Medicine, Seoul, Korea
}

Purpose: We analyzed the clinical data of T3 colorectal cancer patients to assess whether T3 subdivision correlates with node $(\mathrm{N})$ or metastasis $(\mathrm{M})$ staging and stage-independent factors.

Methods: Five hundred fifty-five patients who underwent surgery for primary colorectal cancer from January 2003 to December 2009 were analyzed for T3 subdivision. T3 subdivision was determined by the depth of invasion beyond the outer border of the proper muscle (T3a, <1 mm; T3b, 1 to $5 \mathrm{~mm}$; T3c, $>5$ to $15 \mathrm{~mm}$; T3d, $>15 \mathrm{~mm}$ ). We investigated the correlation between $\mathrm{T} 3$ subdivision and $\mathrm{N}, \mathrm{M}$ staging and stage-independent prognostic factors including angiolymphatic invasion (ALI), venous invasion (VI) and perineural invasion (PNI).

Results: The tumors of the 555 patients were subclassified as T3a in 86 patients (15.5\%), T3b in 209 patients (37.7\%), T3c in 210 patients $(37.8 \%)$ and T3d in 50 patients (9.0\%). The nodal metastasis rates were $39.5 \%$ for T3a, $56.5 \%$ for T3b, $75.7 \%$ for T3c and $74.0 \%$ for T3d. The distant metastasis rates were $7.0 \%$ for T3a $9.1 \%$ for T3b, $27.1 \%$ for T3c and $40.0 \%$ for T3d. Both N and M staging correlated with T3 subdivision (Spearman's rho $=0.288,0.276$, respectively; $\mathrm{P}<0.001$ ). Other stage-independent prognostic factors correlated well with T3 subdivision (Spearman's rho $=0.250, \mathrm{P}<0.001$ for ALI; rho $=0.146, \mathrm{P}<0.001$ for VI; rho $=0.271, \mathrm{P}<0.001$ for PNI).

Conclusion: Subdivision of T3 colorectal cancer correlates with nodal and metastasis staging. Moreover, it correlates with other prognostic factors for colorectal cancer.

Keywords: T3 subdivision; Colorectal neoplasms; Neoplasm staging

\section{INTRODUCTION}

The subdivisions of colorectal cancer and the T staging system have been extensively investigated due to the premise that poorer prognoses are correlated with the depth of tumor invasion [1]. This issue was first raised by the International Documentation System and the International Comprehensive Anatomical Terminology

Received: September 22, 2011 - Accepted: May 17, 2012

Correspondence to: Seung-Yong Jeong, M.D.

Department of Surgery, Seoul National University Hospital, Seoul National University College of Medicine, 101 Daehak-ro, Jongno-gu, Seoul 110-744, Korea

Tel: +82-2-2072-0152, Fax: +82-2-766-3975

E-mail: syjeong@snu.ac.kr

(C) 2012 The Korean Society of Coloproctology

This is an open-access article distributed under the terms of the Creative Commons Attribution NonCommercial License (http://creativecommons.org/licenses/by-nc/3.0) which permits unrestricted noncommercial use, distribution, and reproduction in any medium, provided the original work is properly cited. in 1991 [2]. About a decade later in 2003, a T3 optional subdivision was proposed by the Union Internationale Contre le Cancer [3-6].

In 2001, a proposal regarding the division of $\mathrm{T} 3$ cancers into two subgroups based on a standard 5-mm depth of invasion into the muscularis propria was made [7]. This proposal was practiced in selected groups to predict both prognosis and local recurrence $[4$, 6]. In spite of these trials, the subdivision of $\mathrm{T} 3$ was not adopted by the American Joint Committee on Cancer (AJCC) in 2002 [8] and in 2010 [9], and it still has not been applied as the standard in the United States $[9,10]$. Meanwhile, the subdivisions of T4a and T4b, presented by the AJCC in 2010, were based on accumulated data [9]. To clarify the ambiguity of T3 colon cancer prognoses, supplementing the existing tumor-node-metastasis (TNM) system to improve the success rate of medical treatments for these tumors is important $[4,5,7]$. The aim of this study is to assess whether the T3 subdivision correlates with node $(\mathrm{N})$ or metastasis (M) staging and other stage-independent factors. 


\section{METHODS}

We retrospectively reviewed clinicopathologic records of $592 \mathrm{pa}-$ tients who had undergone surgery for a pathologically proven T3 primary colorectal adenocarcinoma with valid information on the T3 subclassification at the Department of Surgery, Seoul National University Hospital, between January 2003 and December 2009. Among them, we excluded patients with hereditary nonpolyposis colorectal cancer $(n=4)$, familial adenomatous polyposis $(n=7)$, and synchronous or metachronous malignancies other than colorectal cancer $(\mathrm{n}=26)$. Finally, 555 patients $(393$ men and 162 women; mean age, $60.8 \pm 11.9$ years; range, 23 to 91 years) were included for analysis.

The category of pT3 was subdivided according to the histological measurement of the maximal tumor invasion beyond the outer border of the muscularis propria (T3a, $<1 \mathrm{~mm}$; T3b, 1 to $5 \mathrm{~mm}$; T3c, $>5$ to $15 \mathrm{~mm}$; T3d, $>15 \mathrm{~mm}$ ). The specimen slide was observed at a magnification of 40 times. An imaginary line was drawn horizontally extending from the normal muscularis propria next to the lesion. The depth of the lesion infiltrating under that line was measured. Fig. 1 shows the pathologic specimens of T3a, T3b, T3c and T3d tumors. Clinico-demographic and the histopathologic parameters, including the location of the tumor, histologic type and grade, angiolymphatic invasion (ALI), venous invasion (VI), perineural invasion (PNI) and tumor stage, were retrospectively
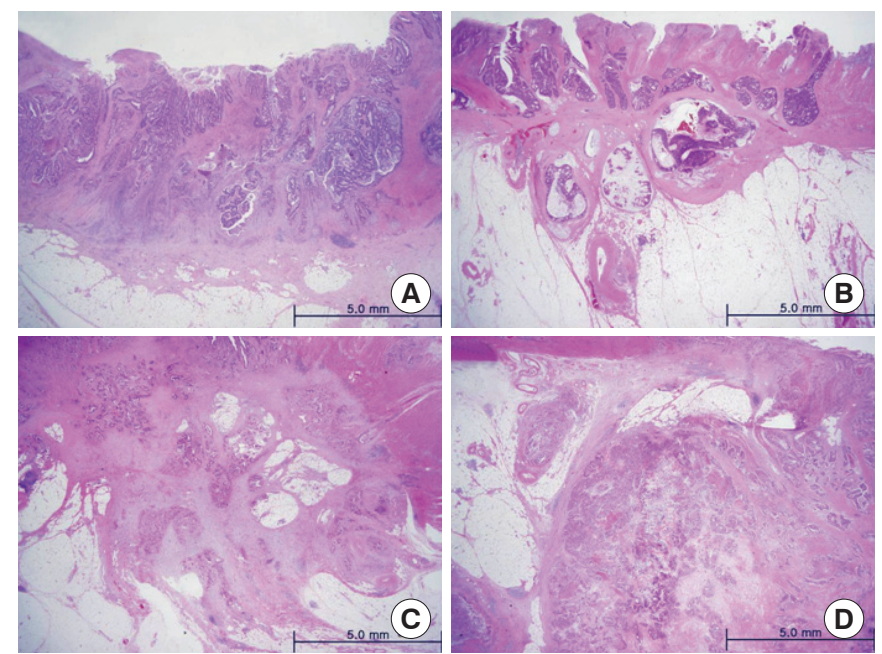

Fig. 1. Histologic features of T3 subdivision. T3 tumors are those that invade through the muscularis propria into the subserosa or into nonperitonealized pericolic or perirectal tissues. T3a are tumors with invasion of less than $1 \mathrm{~mm}(<1 \mathrm{~mm})$ beyond the outer border of muscularis propria (A). T3b are tumors with invasion of $1 \mathrm{~mm}$ or more but does not exceed $5 \mathrm{~mm}$ (1-5 $\mathrm{mm}$ ) beyond the outer border of muscularis propria (B). T3c invades more than $5 \mathrm{~mm}$ but not more than $15 \mathrm{~mm}(>5-15 \mathrm{~mm}$ ) beyond the outer border of the muscularis propria (C). Invasion of T3d exceeds $15 \mathrm{~mm}(>15 \mathrm{~mm})$ beyond the outer border of the muscularis propria (D). reviewed. Tumor stage was determined using the 6th AJCC TNM system [8]. Tumor grade was categorized as low-grade (well or moderately differentiated) and high-grade (poorly differentiated, anaplastic, or undifferentiated). The stage-independent factors were classified using two categories: no invasion and invasion [11]. Correlations among the aforementioned factors were based on Spearman correlation analyses (Spearman correlation coefficient). A perfect Spearman correlation of +1 or -1 occurs when each

Table 1. Clinicopathologic characteristics

\begin{tabular}{|c|c|}
\hline Variable & No. (\%) \\
\hline \multicolumn{2}{|l|}{ Gender } \\
\hline Male & $393(70.8)$ \\
\hline Female & $162(29.8)$ \\
\hline \multicolumn{2}{|l|}{ Age (yr) } \\
\hline Mean (SD) & $60.8(11.9)$ \\
\hline \multicolumn{2}{|l|}{ Location of tumor } \\
\hline Colon & $110(19.8)$ \\
\hline Rectum & 445 (80.2) \\
\hline \multicolumn{2}{|l|}{ T3 categories } \\
\hline Т3а & $86(15.5)$ \\
\hline T3b & $209(37.7)$ \\
\hline T3c & $210(37.8)$ \\
\hline T3d & $50(9.0)$ \\
\hline \multicolumn{2}{|l|}{$\mathrm{N}$ stage } \\
\hline NO & $207(37.3)$ \\
\hline N1 & $208(37.5)$ \\
\hline N2 & $140(25.2)$ \\
\hline \multicolumn{2}{|l|}{ M stage } \\
\hline M0 & 453 (81.6) \\
\hline M1 & $102(18.4)$ \\
\hline \multicolumn{2}{|c|}{ Angiolymphatic invasion } \\
\hline No & $257(46.3)$ \\
\hline Yes & $248(53.7)$ \\
\hline \multicolumn{2}{|l|}{ Venous invasion } \\
\hline No & $399(71.9)$ \\
\hline Yes & $156(28.1)$ \\
\hline \multicolumn{2}{|l|}{ Perineural invasion } \\
\hline No & $345(62.2)$ \\
\hline Yes & 210 (37.8) \\
\hline \multicolumn{2}{|l|}{ Grade } \\
\hline Low-grade $(\mathrm{G} 1,2)$ & $526(94.8)$ \\
\hline High-grade $(G 3,4)$ & $14(2.5)$ \\
\hline Total & 555 \\
\hline
\end{tabular}

$\mathrm{N}$, node; $\mathrm{M}$, metastasis; SD, standard deviation. 
variable is a perfect monotone function of the other. P-values less than 0.05 were regarded as statistically significant. All of the statistics were performed using IBM SPSS ver. 19 (IBM Co., Armonk, NY, USA).

\section{RESULTS}

\section{Patients and tumor characteristics}

For the 555 patients, tumors were subclassified as T3a in 86 (15.5\%), T3b in 209 (37.7\%), T3c in 210 (37.8\%) and T3d in 53 (9.0\%) patients. Clinicopathologic characteristics of the patients are listed in Table 1 . Lymph node metastasis was found in $62.7 \%$ of the patients and distant metastasis in $18.4 \%$ of the patients. The mean number of harvested lymph nodes was $16.8 \pm 9.9$. Curative surgery was performed in $87.6 \%$ of the patients. Overall stagings of the patients were IIA in 197 (35.5\%), IIIB in 178 (32.1\%), IIIC in $102(18.4 \%)$, and IV in $78(14.1 \%)$ patients.

\section{Correlation between $\mathrm{T} 3$ subdivision and $\mathrm{N}$ and $\mathrm{M}$ stages}

The rate of lymph node metastases increased in the advanced T3 subdivision (Table 2). The nodal stage correlated well with T3 subdivision (Spearman's rho $=0.288, \mathrm{P}<0.001$ ). The distant metastasis rates were $7.0 \%$ for $\mathrm{T} 3 \mathrm{a}, 9.1 \%$ for $\mathrm{T} 3 \mathrm{~b}, 27.1 \%$ for $\mathrm{T} 3 \mathrm{c}$, and
$40.0 \%$ for T3d lesions. M stage also correlated well with the T3 subdivision (Spearman's rho $=0.276, \mathrm{P}<0.001$ ).

\section{Correlation between $\mathrm{T} 3$ subdivision and stage-independent factors}

The correlation coefficients (Spearman's rho) between the T3 subdivision and stage-independent factors were $0.250, \mathrm{P}<0.001$ for ALI; 0.146, P $<0.001$ for VI; $0.271, \mathrm{P}<0.001$ for PNI. T3 subdivision also demonstrated a tendency to have a positive linear correlation with stage-independent factors. As the stage advanced, the percentage of ALI, VI and PNI increased (Table 3).

\section{DISCUSSION}

The recent boom of personal health check-ups and the popularization of colonoscopy have facilitated detection of early-stage colorectal cancer, but still the majority of patients encountered in clinics have advanced tumors. From 2003 to 2009, 3,913 patients underwent surgery for colorectal cancer at the Department of Surgery, Seoul National University Hospital. Among them, the majority of patients $(68.2 \%)$ had tumors that had invaded beyond the muscle layers (T3, 2,309 patients [59.0\%]; T4, 360 patients [9.2\%]). Although T3 tumors occupy more than half of all can-

Table 2. N, M stage according to T3 subdivision

\begin{tabular}{|c|c|c|c|c|c|}
\hline & Total & T3a $(n=86,15.5 \%)$ & T3b $(n=209,37.7 \%)$ & T3c $(n=210,37.8 \%)$ & T3d $(n=50,9.0 \%)$ \\
\hline \multicolumn{6}{|c|}{$\mathrm{N}$ stage } \\
\hline NO & 207 (37.3) & $52(60.5)$ & $91(43.5)$ & $51(24.3)$ & $13(26.0)$ \\
\hline $\mathrm{N}+$ & $348(62.7)$ & 34 (39.5) & $118(56.5)$ & $159(75.7)$ & $37(74.0)$ \\
\hline \multicolumn{6}{|c|}{ M stage } \\
\hline M0 & $453(81.6)$ & $80(93.0)$ & $190(90.9)$ & $153(72.9)$ & $30(81.6)$ \\
\hline M1 & $102(18.4)$ & $6(7.0)$ & $19(9.1)$ & $57(27.1)$ & $20(40.0)$ \\
\hline
\end{tabular}

Values are presented as number (\%).

$\mathrm{N}$, node; M, metastasis.

Table 3. Stage-independent factors according to T3 subdivision

\begin{tabular}{|c|c|c|c|c|c|}
\hline & Total & T3a $(n=86,15.5 \%)$ & T3b $(n=209,37.7 \%)$ & T3c $(n=210,37.8 \%)$ & T3d $(n=50,9.0 \%)$ \\
\hline \multicolumn{6}{|c|}{ Angiolymphatic invasion } \\
\hline ALI- & $257(52.1)$ & $56(70.0)$ & $117(64.3)$ & $68(34.9)$ & $16(33.3)$ \\
\hline $\mathrm{ALI}+$ & $248(47.9)$ & $24(30.0)$ & $65(35.7)$ & $127(65.1)$ & $32(66.7)$ \\
\hline \multicolumn{6}{|c|}{ Venous invasion } \\
\hline $\mathrm{VI}-$ & $399(81.9)$ & $75(94.9)$ & $150(85.2)$ & $143(77.7)$ & $31(64.6)$ \\
\hline $\mathrm{VI}+$ & $88(18.1)$ & $4(5.1)$ & $26(14.8)$ & $41(22.3)$ & $17(35.4)$ \\
\hline \multicolumn{6}{|c|}{ Perineural invasion } \\
\hline PNI- & $345(69.8)$ & $75(94.9)$ & $142(80.7)$ & $104(54.7)$ & $24(49.0)$ \\
\hline $\mathrm{PNI}+$ & $149(30.2)$ & $4(5.1)$ & 34 (19.3) & $86(45.3)$ & $25(51.0)$ \\
\hline
\end{tabular}

Values are presented as number (\%).

$\mathrm{ALI}$, angiolymphatic invasion; VI, venous invasion; PNI, perineural invasion. 
cers, they are classified as only one stage whereas T4 tumors are divided into two groups, T4a and T4b.

Several reports have demonstrated a prognostic heterogeneity among T3 colorectal cancers. Some authors indicated the depth of extramural fat invasion as a significant prognostic factor $[3,5$, 12-17]. In 2001, the Erlangen Registry of Colorectal Carcinoma (ERCRC) and Study Group for Colorectal Carcinoma (SGCRC) Studies proposed that the perimuscular invasion should be subdivided into $\leq 5 \mathrm{~mm}, 5 \mathrm{~mm}$ to $15 \mathrm{~mm}$, and $\geq 15 \mathrm{~mm}$ according to the histological measurements. T3 tumors were subdivided into T3a and T3b by using a 5-mm cutoff point for invasion depth of T3 tumors in stage II colon cancer. The local recurrence rate was shown to be significantly higher for T3b tumors than for T3a tumors in the ERCRC data, but a similar result was not demonstrated in the SGCRC data [7, 12]. Willet et al. [5] subdivided T3 lesions into 3 groups by using the depth of invasion: $<2 \mathrm{~mm}, 2$ to $8 \mathrm{~mm}$, and $\geq 8 \mathrm{~mm}$, and they demonstrated a significant difference in the recurrence-free survival ( $87 \%$ vs. $57 \%$ vs. $36 \%$, respectively).

In addition, various prognostic cutoff points such as $3 \mathrm{~mm}, 4 \mathrm{~mm}$, and $6 \mathrm{~mm}$ have been proposed for the subdivision of T3 colorectal cancer $[3,13,14]$. Furthermore, by using a univariate analysis, Burdy et al. [18] showed that mesocolic invasion of more than $1 \mathrm{~cm}$ was significantly associated with a higher risk of tumor recurrence in T3-4 node-negative colon cancer. Although multivariate analysis showed that other factors were also independently associated with tumor recurrence, that the depth of mesocolic invasion has been considered as a significant predictive factor for tumor recurrence is meaningful.

The depth of local tumor invasion remains as an independent and significant prognostic factor even in the presence of lymph node metastasis. Lymph node metastasis has been recognized as the main clinical indicator for predicting survival in curativelyresected colorectal cancer [19]. Several reports demonstrated that the extent of the primary tumor was related with nodal metastasis, distant metastasis, or stage-independent prognostic factors. Wong et al. [20] explored whether depth of invasion held important prognostic importance both in the presence and the absence of nodal or distant metastases in colon cancer. They demonstrated that the depth of local tumor invasion correlated strongly with nodal involvement, rates of extramural VI, poor differentiation, and distant metastasis. In patients with lymph node or distant metastasis (43\%), the depth of tumor invasion had a significant impact on overall survival [20]. In this study, all T-staged colorectal cancers were included and were divided according to the conventional TNM system.

In the present study, we demonstrated that the T3 subdivision had a statistically significant correlation with other factors, including $\mathrm{N}$ and $\mathrm{M}$ staging, but that the correlation coefficients were not so high. This implies that several other factors that influence the tumor biology and the oncologic outcomes may exist. To date, many studies have focused on finding surrogate markers for the prognosis of colorectal cancer, and many of them included mo- lecular markers. Mutch [21] advocated that tumor staging and molecular markers, including gene expression profiling, have significant correlations and that these molecular markers should be incorporated in a future staging system. However, due to the cost and the technical complexity in evaluating these markers, not every clinic has the capability of testing for the "new" markers.

The stage groups within the TNM classification are divided according to the overall survival rates, and nodal and distant metastasis differentiates stage III from IV. The TNM classification stratifies patients according to the risk of recurrence or metastasis and identifies patients who will benefit from more aggressive adjuvant therapy. Therefore, elucidating clinicopathologic factors that have correlations with lymph node or distant metastasis is important. Especially, factors that can be easily evaluated, such as tumor invasion depth in the present study, have greater usefulness.

In conclusion, we demonstrated that subdivision of T3 colorectal cancer correlates well with nodal and metastasis staging. It also correlates well with other already known prognostic factors for colorectal cancer. We can postulate that invasion depth may influence the prognosis for patients even when they have the same T3staged tumors, but this should be further verified with a future study on patient survival and recurrence.

\section{CONFLICT OF INTEREST}

No potential conflict of interest relevant to this article was reported.

\section{REFERENCES}

1. Newland RC, Dent OF, Lyttle MN, Chapuis PH, Bokey EL. Pathologic determinants of survival associated with colorectal cancer with lymph node metastases. A multivariate analysis of $579 \mathrm{pa}-$ tients. Cancer 1994;73:2076-82.

2. Fielding LP, Arsenault PA, Chapuis PH, Dent O, Gathright B, Hardcastle JD, et al. Clinicopathological staging for colorectal cancer: an International Documentation System (IDS) and an International Comprehensive Anatomical Terminology (ICAT). J Gastroenterol Hepatol 1991;6:325-44.

3. Cawthorn SJ, Parums DV, Gibbs NM, A'Hern RP, Caffarey SM, Broughton CI, et al. Extent of mesorectal spread and involvement of lateral resection margin as prognostic factors after surgery for rectal cancer. Lancet 1990;335:1055-9.

4. Krook JE, Moertel CG, Gunderson LL, Wieand HS, Collins RT, Beart RW, et al. Effective surgical adjuvant therapy for high-risk rectal carcinoma. N Engl J Med 1991;324:709-15.

5. Willett CG, Badizadegan K, Ancukiewicz M, Shellito PC. Prognostic factors in stage T3N0 rectal cancer: do all patients require postoperative pelvic irradiation and chemotherapy? Dis Colon Rectum 1999;42:167-73.

6. Wittekind C. TNM supplement: a commentary on uniform use. 3rd ed. Hoboken: Wiley-Liss; 2003.

7. Merkel S, Wein A, Gunther K, Papadopoulos T, Hohenberger W, 
Hermanek P. High-risk groups of patients with Stage II colon carcinoma. Cancer 2001;92:1435-43.

8. Greene FL, Page DL, Fleming ID, Fritz AG, Balch CM, Haller DG, et al. AJCC cancer staging manual. 6th ed. New York: SpringerVerlag; 2002.

9. Edge SB, Compton CC. The American Joint Committee on Cancer: the 7th edition of the AJCC cancer staging manual and the future of TNM. Ann Surg Oncol 2010;17:1471-4.

10. Washington MK. Colorectal carcinoma: selected issues in pathologic examination and staging and determination of prognostic factors. Arch Pathol Lab Med 2008;132:1600-7.

11. Quah HM, Chou JF, Gonen M, Shia J, Schrag D, Landmann RG, et al. Identification of patients with high-risk stage II colon cancer for adjuvant therapy. Dis Colon Rectum 2008;51:503-7.

12. Merkel S, Mansmann U, Siassi M, Papadopoulos T, Hohenberger $\mathrm{W}$, Hermanek P. The prognostic inhomogeneity in pT3 rectal carcinomas. Int J Colorectal Dis 2001;16:298-304.

13. Picon AI, Moore HG, Sternberg SS, Minsky BD, Paty PB, Blumberg D, et al. Prognostic significance of depth of gross or microscopic perirectal fat invasion in T3 N0 M0 rectal cancers following sharp mesorectal excision and no adjuvant therapy. Int J Colorectal Dis 2003;18:487-92.

14. Miyoshi M, Ueno H, Hashiguchi Y, Mochizuki H, Talbot IC. Extent of mesorectal tumor invasion as a prognostic factor after curative surgery for T3 rectal cancer patients. Ann Surg 2006;243:
492-8.

15. Katsumata D, Fukui H, Ono Y, Ichikawa K, Tomita S, Imura J, et al. Depth of tumor invasion in locally advanced rectal cancer correlates with patients' prognosis: the usefulness of elastic stain for its measurement. Surg Today 2008;38:115-22.

16. Yoshida K, Yoshimatsu K, Otani T, Yokomizo H, Ogawa K. The depth of tumor invasion beyond the outer border of the muscularis propria as a prognostic factor for T3 rectal/rectosigmoid cancer. Anticancer Res 2008;28(3B):1773-8.

17. Tokoro T, Okuno K, Hida J, Ishimaru E, Ueda K, Yoshifuji T. Depth of mesorectal invasion has prognostic significance in T3N0 low rectal cancer. Hepatogastroenterology 2009;56:124-7.

18. Burdy G, Panis Y, Alves A, Nemeth J, Lavergne-Slove A, Valleur P. Identifying patients with T3-T4 node-negative colon cancer at high risk of recurrence. Dis Colon Rectum 2001;44:1682-8.

19. Astler VB, Coller FA. The prognostic significance of direct extension of carcinoma of the colon and rectum. Ann Surg 1954;139: 846-52.

20. Wong SK, Jalaludin BB, Henderson CJ, Morgan MJ, Berthelsen AS, Issac MM, et al. Direct tumor invasion in colon cancer: correlation with tumor spread and survival. Dis Colon Rectum 2008; 51:1331-8.

21. Mutch MG. Molecular profiling and risk stratification of adenocarcinoma of the colon. J Surg Oncol 2007;96:693-703. 